\title{
Lung cancer in Yorkshire chrome platers, 1972-97
}

\author{
Tom Sorahan, J Malcolm Harrington
}

\begin{abstract}
Objectives-To investigate mortality from lung cancer in chrome platers, a group exposed to chromic acid.

Methods-The mortality of a cohort of 1087 chrome platers (920 men, 167 women) from 54 plants situated in the West Riding of Yorkshire, United Kingdom, was investigated for the period 197297. All subjects were employed as chrome platers for $\geqslant 3$ months and all were alive on 31 May 1972. Mortality data were also available for a cohort of 1163 comparison workers with no known occupational exposure to chrome compounds (989 men, 174 women). Information on duration of chrome work and smoking habits collected for a cross sectional survey carried out in 1969-72 were available for 916 $(84.3 \%)$ of the chrome platers; smoking habits were available for 1004 (86.3\%) comparison workers. Two analytical approaches were used, indirect standardisation and Poisson regression.

Results-Based on serial mortality rates for the general population of England and Wales, significantly increased mortality from lung cancer was observed (obs) in male chrome platers (obs 60, expected (exp) 32.5, standardised mortality ratio (SMR) 185, p<0.001) but not in male comparison workers (obs 47, exp 36.9, SMR 127). Positive trends were not shown for duration of employment exposed to chrome, although data on working after 1972 were not available.

Conclusions-Confident interpretation is not possible but occupational exposures to hexavalent chromium may well have been involved in the increased mortality from lung cancer found in this cohort of chrome platers.

(Occup Environ Med 2000;57:385-389)
\end{abstract}

Keywords: chromium plating; lung cancer

In 1990, a working group of the International Agency for Research on Cancer (IARC) concluded that there was sufficient evidence in humans for the carcinogenicity of chromium [VI] compounds "as encountered in the chromate production, chromate pigment production, and chromium plating industries." 1 Eight reports relating to five cohort studies of chrome platers were available for this evaluation. $^{2-9}$

Since the IARC report, findings from two of the above cohorts ${ }^{2-9}$ have been updated..$^{10}$ The study of 626 chrome platers from 415 factories in Japan reported a non-significant excess of lung cancer (observed (obs) eight, expected (exp) 4.3). ${ }^{10}$ The updated United Kingdom study of 1201 chrome bath workers from a single factory reported a significantly increased standardised mortality ratio (SMR) for lung cancer (obs 40, exp 25.4, p<0.01) and a significant positive trend $(\mathrm{p}<0.05)$ for risk and cumulative duration of chrome bath work. ${ }^{11}$ Also, a new cohort study of 265 workers from 40 small plating factories in Japan has been reported. ${ }^{12}$ Only one death from lung cancer was reported (exp 0.90), although the very low SMR from all causes (obs eight, exp 25.2) may indicate inadequate follow up. The present report updates the only other available United Kingdom cohort of chromium platers. $^{34}$

\section{Materials and methods}

MATERIALS

In the period 20 February 1969 to 31 May 1972, the late Dr Harold Royle identified cohorts of chrome platers from 54 plants in the West Riding of Yorkshire, so that risks of mortality from lung cancer and other neoplastic disease in chrome platers could be investigated. ${ }^{3}$ A cross sectional morbidity study of respiratory symptoms, respiratory diseases, and irritant effects on the skin and nasal mucosa was also carried out. ${ }^{4}$ Details of data collection have already been described, ${ }^{3}{ }^{4}$ with further information available to us in an unpublished thesis. ${ }^{13}$

The principal plating activity of all 54 plants was chrome plating and the hazard common to all workers included in the plater cohort was exposure to hexavalent chromium in the form of chromic acid mist. Also, 49 of the plants used nickel, 18 cadmium, and smaller numbers of plants also used zinc, tin, copper, silver, gold, brass, or rhodium. Lead was not used at any of the plants and four plants (including one of the largest) only used chromium. The baths in five of the plants were either manually operated (open vat) or semiautomatic, fully automated in three, semiautomatic in two, and manually operated in the remaining 44 plants.

Industrial hygiene surveys were carried out in $1969-70$ at 42 of the participating plants by the Occupational Hygiene Service of Manchester University. ${ }^{4}$ Area air samples (static samplers) were taken at breathing zone height, and in all but two plants the chromic acid air content was $<0.03 \mathrm{mg} . \mathrm{m}^{-3}$. The two exceptions were large plants, and in both the then threshold limit value (TLV) for chromic acid of 0.1 $\mathrm{mg} \cdot \mathrm{m}^{-3}$ was exceeded.

The plater cohort included all those current and former chrome platers who had been so employed for at least 3 consecutive months. Other workers such as wirers and unwirers were included if, after inspection of the plating 
shops, they were also judged to be exposed to chromic acid-for example, working next to the chrome baths. In several plants, polishers worked in a separate room, or their working area was partitioned off; such work did not qualify for entry to the plater cohort. The cohort was enumerated and identifying particulars were assembled with information from personnel files, old wage books, health registers (used by appointed factory doctors for their periodic inspections of chrome workers), plant managers, and foremen.

The 299 chrome platers working at the time of the original data collection were individually matched, with respect to sex and age (usually within 5 years, often within 2 years), to manual workers who had never had any industrial contact with chrome (table 1). The comparison workers (controls) were drawn mainly from the larger firms, where chromium plating was only a small part of the activities of the companies. Also, a few controls were identified from the British Rail Carriage Works at York and Redfearn National Glass Limited of York. The 1064 ex-platers were individually matched, for sex, age and year of leaving employment with ex-workers from the two companies already mentioned. A few platers were later found to have worked for $<3$ months and a few duplicate entries were also removed, so that control numbers exceeded those of platers (table 1 ).

In the period 1969-72, current platers and matched comparison workers were interviewed at their place of work. Also, with the assistance of medical officers of health, trained health visitors sought permission from the former employees (platers and controls) to carry out interviews at their homes. The Medical Research Council (MRC) questionnaire on respiratory symptoms (1966) was used for all interviews; this questionnaire includes sections on tobacco smoking and occupation (coalmine, quarry, foundry, pottery, asbestos, etc). Additional information was also sought on bronchial asthma, hay fever, nasal ulceration, and skin ulceration. Interview data were obtained for a total of $997(73.1 \%)$ platers and 1117 $(80.9 \%)$ comparison workers. Interviews could not be arranged for ex-workers whose current address could not be traced and only 65 platers and 54 comparison workers refused to participate in the interviews.

In 1981, an audit and refinement of all available survey materials was carried out to maximise the future usefulness of this survey.

Table 1 Development of current study population

\begin{tabular}{lcc}
\hline Category & Chrome platers & $\begin{array}{l}\text { Comparison workers } \\
\text { (controls) }\end{array}$ \\
\hline In post & 299 & 299 \\
Left employment & 1064 & 1081 \\
Considered for prospective mortality study & 1363 & 1380 \\
Removed from prospective mortality study: & 82 & 15 \\
$\quad$ Untraced at NHSCR $\dagger$ & 1 & 13 \\
Member of HM Forces† & 109 & 85 \\
Deceased $\dagger$ & 42 & 68 \\
Emigrated $\dagger$ & 42 & 36 \\
After reassessment of original study materials $\ddagger$ & 1087 & 1163 \\
Final study cohort & &
\end{tabular}

*At time of factory visits carried out during the period 20 February 1969 to 31 May 1972.

tAt the start of follow up on 1 June 1972.

$\ddagger$ Carried out in 1981 , see text.
This work included a reconciliation of various lists and double-checking of existing computerised data. A summary of this review is still available; a further 42 platers and 36 comparison workers had been removed from the mortality study because of duplicate entries and incorrect classifications. Unfortunately, the only computerised information from the MRC questionnaires related to tobacco consumption, and the original completed questionnaires were apparently not preserved. The analysis reported here relates to 1087 platers (920 men, 167 women) and 1163 comparison workers (989 men, 174 women, table 1 ).

The Office for National Statistics (ONS) provided information on the vital status of each study subject up to the closing date of the survey (31 December 1997): 1364 subjects were alive, 14 subjects had emigrated, and 872 subjects were dead. (Many subjects who had emigrated before June 1972, had already been removed from the study, table 1.) The underlying cause of death was provided by the ONS, coded to the 8th revision of the international classification of disease (ICD-8). Information was also computerised for those deaths for which either lung cancer $(n=4)$ or mesothelioma $(n=0)$ was mentioned on the death certificate, but not selected as the underlying cause. Vital status as recorded in the study computer file was double checked with computerised information at the ONS.

\section{METHODS}

\section{External standard (SMR)}

Expected numbers of deaths were calculated by applying sex, age and period specific mortality rates for England and Wales to corresponding person-years at risk. Each study subject contributed person-years at risk from 1 June 1972 to the closing date of the study (31 December 1997), death, emigration, or date last known alive, whichever was the earliest. The SMRs were calculated as the ratio of observed deaths to expected deaths, expressed as a percentage. These procedures were carried out with the PERSONYEARS programme. Data were censored at age 85 years for reasons already described. ${ }^{14}$

\section{INTERNAL STANDARD}

For the internal analyses, mortality rates of platers were compared directly with those of comparison workers. Lung cancers mentioned in any part of the death certificate were selected, thereby introducing four cases unavailable to the underlying cause analyses. Several variables were considered to have the potential for influencing mortality within the cohort: attained age, calendar period, employment status at the time of the original 1969-72 survey (still employed or left employment), duration of chrome work, and smoking habits at the time of the survey (information on factory, year of first chrome work, and type of chrome bath were unavailable). Each variable was categorised into several levels. The models were constructed such that there was at least one death observed at each level of each 
variable. Any adjustments were made before any statistical modelling was carried out.

The EPICURE computer program was used both to provide person-years at risk and numbers of deaths for all combinations of all levels of the selected variables ${ }^{15}$ and to carry out statistical modelling by means of Poisson regression, ${ }^{16}$ calculating point estimates of relative risk (RR) for categories of work history variables with and without adjustment for other variables.

All preceding methods ignore the individual matching of chrome platers with comparison workers. A matched analysis was also carried out, equivalent to the Mantel-Haenszel technique applied to matched case-control studies, or McNemar's test of discordant pairs. Matched pairs in which neither subject died from the cause under investigation are statistically uninformative and were ignored. The only informative pairs are those in which one subject (plater or comparison worker) died from the cause under investigation and the matched subject was still alive at the time of that death (any later cause of death is irrelevant to the analysis and is ignored). According to the null hypothesis of no effect of chrome plating upon mortality, informative pairs were to be evenly split between those in which the death relates to a plater $\left(n_{1}\right)$ and those in which the death relates to a comparison worker $\left(\mathrm{n}_{2}\right)$. The ratio $n_{1} / n_{2}$ provides an estimate of $R R$.

\section{Results}

EXTERNAL STANDARD

Mortality from all causes in the total study cohort, analysed by age at death, suggested no obvious evidence of inadequate tracing of deaths (<60 y: SMR 119, obs 204; 60-69 y: SMR 100, obs 251; 70-79 y: SMR 118, obs 289; 80-84 y: SMR 117, obs 72). A similar analysis by year of death also provided unremarkable findings (1972-80: SMR 120, obs 237; 1981-90: SMR 109, obs 322; 1991-97: SMR 109, obs 257).

Table 2 shows observed and expected numbers of deaths by site of cancer and sex for chrome platers and comparison workers. There was a highly significant excess of lung cancer $(p<0.001)$ in male chrome platers (SMR 185, obs 60) but among female chrome platers only 2.1 such deaths were expected (SMR 96, obs 2 ). Other significant excesses are shown in male chrome platers for all cancers and all causes, and in female chrome platers for all non-cancers and all causes. In men, the difference in lung cancer SMRs between chrome platers and comparison workers approached formal levels of significance $\left(\chi_{(1)}^{2}=3.67\right.$, $\mathrm{p}=0.06)$. Findings for comparison workers were unexceptional except for a highly significant excess of mesothelioma in men (SMR 1235, obs 7).

Table 3 shows observed and expected numbers of deaths from lung cancer for male chrome platers by duration of chrome work and by employment status (current platers $v$ former platers). There was no trend of risk increasing with duration of exposed employment (all chrome platers, three levels of known duration: $\quad\left(\chi_{(1)}^{2}=1.44, \mathrm{p}=0.23\right)$. Increased SMRs are shown for those platers with unknown durations of chrome work.

INTERNAL STANDARD

Table 4 shows RRs of mortality for lung cancer and for all other causes, adjusted for sex and age, by type of worker, smoking habit, and employment status (still employed or left employment). The table summarises the results of eight separate analyses (left hand column of RRs, six separate analyses: right

Table 2 Mortality of chrome platers and controls, 1972-97

\begin{tabular}{|c|c|c|c|c|c|c|c|}
\hline \multirow[b]{2}{*}{ Cause of death } & \multirow[b]{2}{*}{$I C D-8$} & \multicolumn{3}{|c|}{ Chrome platers } & \multicolumn{3}{|c|}{ Comparison workers } \\
\hline & & Obs & $\operatorname{Exp}$ & SMR $(95 \% C I)$ & $\mathrm{Obs}$ & $\operatorname{Exp}$ & SMR $(95 \% C I)$ \\
\hline \multicolumn{8}{|l|}{ Men: } \\
\hline \multicolumn{8}{|l|}{ Cancers: } \\
\hline Stomach & 150 & 12 & 7.1 & $168(87$ to 294$)$ & 5 & 8.0 & 63 (20 to 146$)$ \\
\hline Large intestine & 153 & 8 & 6.0 & $134(58$ to 265$)$ & 9 & 6.8 & $133(61$ to 253$)$ \\
\hline Rectum & 154 & 6 & 3.9 & $154(56$ to 334$)$ & 3 & 4.4 & 68 (14 to 198$)$ \\
\hline Nose and sinuses & 160 & 1 & 0.15 & $687(17$ to 3830$)$ & 0 & 0.17 & $0-$ \\
\hline Larynx & 161 & 1 & 0.9 & $117(3$ to 650$)$ & 1 & 1.0 & 102 (3 to 569$)$ \\
\hline Lung and bronchus & 162 & $60^{\star \star \star}$ & 32.5 & $185(141$ to 238$)$ & 47 & 36.9 & $127(94$ to 169$)$ \\
\hline Pleura & 163.1 & 1 & 0.48 & 207 (5 to 1152$)$ & $7^{\star \star \star}$ & 0.57 & 1235 (497 to 2545$)$ \\
\hline Prostate & 185 & 7 & 6.6 & $106(43$ to 219$)$ & 7 & 7.3 & 96 (38 to 197$)$ \\
\hline Bladder & 188 & 3 & 3.5 & $86(18$ to 252$)$ & 6 & 3.9 & $154(56$ to 335$)$ \\
\hline All other neoplasms & rem $140-239$ & 23 & 29.1 & $79(50$ to 119$)$ & 33 & 33.3 & $99(68$ to 139$)$ \\
\hline All neoplasms & $140-239$ & $122^{\star \star}$ & 90.2 & 135 ( 112 to 162$)$ & 118 & 102.3 & 115 (95 to 138$)$ \\
\hline All non-cancers & & 241 & 217.4 & $111(97$ to 126$)$ & 238 & 241.8 & 98 (86 to 112$)$ \\
\hline All causes & & $363^{\star \star}$ & 307.6 & $118(106$ to 131$)$ & 356 & 344.1 & $103(93$ to 115$)$ \\
\hline \multicolumn{8}{|l|}{ Women: } \\
\hline \multicolumn{8}{|l|}{ Cancers: } \\
\hline Stomach & 150 & 0 & 0.6 & $0-$ & 1 & 0.7 & 146 (4 to 816$)$ \\
\hline Large intestine & 153 & 0 & 1.0 & $0-$ & 1 & 1.2 & $86(2$ to 480$)$ \\
\hline Rectum & 154 & 0 & 0.4 & $0-$ & 1 & 0.5 & 203 (5 to 1133$)$ \\
\hline Nose and sinuses & 160 & 0 & 0.02 & $0-$ & 0 & 0.02 & $0-$ \\
\hline Larynx & 161 & 0 & 0.04 & $0-$ & 0 & 0.04 & $0-$ \\
\hline Lung and bronchus & 162 & 2 & 2.1 & 96 (12 to 346$)$ & 3 & 2.5 & 121 (25 to 352$)$ \\
\hline Pleura & 163.1 & 0 & 0.02 & $0-$ & 0 & 0.02 & $0-$ \\
\hline Bladder & 188 & 0 & 0.2 & $0-$ & 1 & 0.3 & 387 (10 to 2158$)$ \\
\hline All other neoplasms & rem $140-239$ & 7 & 7.9 & 89 (36 to 183$)$ & 4 & 9.2 & $43(12$ to 111$)$ \\
\hline All neoplasms & $140-239$ & 9 & 12.3 & 73 (33 to 139$)$ & 11 & 14.5 & $76(38$ to 136$)$ \\
\hline All non-cancers & & $39 \star \star$ & 23.1 & $169(120$ to 231$)$ & 38 & 28.8 & $132(93$ to 181$)$ \\
\hline All causes & & $48^{\star}$ & 35.4 & $136(100$ to 180$)$ & 49 & 43.3 & $113(84$ to 150$)$ \\
\hline
\end{tabular}

${ }^{\star} \mathrm{p}<0.05 ;{ }^{\star \star} \mathrm{p}<0.01 ;{ }^{\star \star \star} \mathrm{p}<0.001$. 
Table 3 Mortality from lung cancert among male chrome platers by employment $\neq$ and by duration of employment exposed to chrome, $1972-97$

\begin{tabular}{|c|c|c|c|c|c|c|c|c|c|}
\hline \multirow{3}{*}{$\begin{array}{l}\text { Duration of } \\
\text { employment exposed } \\
\text { to chrome }\end{array}$} & \multicolumn{6}{|c|}{ Employment $\neq$} & & & \\
\hline & \multicolumn{3}{|c|}{ Current chrome platers $(n=255)$} & \multicolumn{3}{|c|}{ Former chrome platers $(n=665)$} & \multicolumn{3}{|c|}{ Total $(n=920)$} \\
\hline & $O b s$ & $\operatorname{Exp}$ & $\operatorname{SMR}(95 \% C I)$ & Obs & $\operatorname{Exp}$ & $S M R(95 \% C I)$ & Obs & $\operatorname{Exp}$ & $S M R(95 \% C I)$ \\
\hline $3-11(\mathrm{~m})$ & 0 & 0.44 & $0-$ & $11^{\star}$ & 4.87 & $226(113$ to 404$)$ & $11^{\star}$ & 5.31 & 207 (103 to 371$)$ \\
\hline $1-4(y)$ & 5 & 1.88 & 265 (86 to 619$)$ & $14^{\star}$ & 7.02 & $199(109$ to 335$)$ & $19^{\star \star}$ & 8.90 & 213 (129 to 333$)$ \\
\hline$\geqslant 5(y)$ & 12 & 7.53 & $159(82$ to 279$)$ & 7 & 5.96 & 117 (47 to 242$)$ & 19 & 13.49 & $141(85$ to 220$)$ \\
\hline Unknown & 1 & 0.13 & $755-$ & $10^{\star}$ & 4.62 & 216 (104 to 398$)$ & $11^{\star}$ & 4.75 & $232(116$ to 414$)$ \\
\hline Total & $18^{\star}$ & 9.98 & 180 (107 to 285$)$ & $42^{\star \star \star}$ & 22.47 & $187(135$ to 253$)$ & 60 & $32.46^{\star \star \star}$ & 185 (141 to 238$)$ \\
\hline
\end{tabular}

${ }^{\star} \mathrm{p}<0.05 ;{ }^{\star \star} \mathrm{p}<0.01 ;{ }^{\star \star \star} \mathrm{p}<0.001$

+ICD-8 162

¥See footnote ${ }^{\star}$, table 1 .

hand column, two separate analyses). The RR of 1.44 shown for lung cancer in chrome platers $(p=0.05)$ was reduced slightly after additional adjustment for smoking habits and employment status. Smoking habits were an important predictor of risks both for lung cancer (likelihood ratio test (LRT): $p<0.001$ ) and for other causes of death (LRT: $p<0.01$ ). In further analyses (not shown), neither pipe smoking nor cigar smoking was an important predictor of risks of lung cancer. Given the absence of a positive trend between lung cancer SMRs and duration of chrome work, it was not surprising to find no positive trend in the corresponding Poisson regression analysis (not shown).

In the matched analysis, there were 50 matched pairs in which the plater died from lung cancer when the comparison worker was still alive, and 26 matched pairs in which the comparison worker died from lung cancer when the plater was still alive (RR 1.92, 95\% confidence interval ( $95 \%$ CI) 1.14 to 3.28$)$. A similar analysis for all causes other than lung cancer provided 214 matched pairs in which the plater died when the control worker was still alive, and 185 matched pairs in which the control worker died when the chrome plater was still alive (RR $1.16,95 \%$ CI 0.94 to 1.42 ).

A comparison of cigarette smoking habits of 1920 study subjects with those of some 22000 respondents in the general household survey of $1972^{17}$ indicated a higher proportion of current smokers in the plater cohort $(71.8 \%)$ than expected (52.6\%) (adjusted for sex and age). Corresponding percentages for the comparison workers were $64.0 \%$ and $52.5 \%$, respectively. There were more ex-smokers in the comparison workers $(14.8 \%)$ than the platers $(9.8 \%)$.

\section{Discussion}

Mortality from lung cancer was increased in the chrome platers; significantly so when compared with United Kingdom rates of mortality, marginally so compared with comparison

Table 4 Relative risks of mortality from lung cancer and all other causes by type of work and daily consumption of cigarettes, 1972-97

\begin{tabular}{|c|c|c|c|}
\hline Variables & $n$ & $\begin{array}{l}\text { Separate analysist } \\
R R(95 \% \mathrm{CI})\end{array}$ & $\begin{array}{l}\text { Simultaneous analysis } \neq \\
R R(95 \% \mathrm{CI})\end{array}$ \\
\hline \multicolumn{4}{|l|}{ Lung cancer: } \\
\hline \multicolumn{4}{|l|}{ Type of worker: } \\
\hline Comparison workers & 51 & 1.0 & 1.0 \\
\hline Chrome platers & 65 & $1.44(1.00$ to 2.08$)$ & $1.39(0.96$ to 2.00$)$ \\
\hline \multicolumn{4}{|c|}{ Cigarette smoking: daily habit (g/day) $)^{\S:}$} \\
\hline Lifelong non-smoker & 6 & 1.0 & 1.0 \\
\hline $1-4$ & 4 & $5.73^{\star \star}(1.62$ to 20.32$)$ & $5.50^{\star \star}(1.55$ to 19.57$)$ \\
\hline $5-14$ & 21 & $3.15^{\star}(1.27$ to 7.82$)$ & $3.09^{\star}(1.24$ to 7.66$)$ \\
\hline $15-24$ & 46 & $5.58^{\star \star \star}(2.38$ to 13.11$)$ & $5.50^{\star \star \star}(2.34$ to 12.92$)$ \\
\hline$\geqslant 25$ & 19 & $6.01^{\star \star \star}(2.39$ to 15.10$)$ & $5.97^{\star \star \star}(2.37$ to 15.02$)$ \\
\hline Ex-smoker & 4 & $0.84(0.24$ to 2.97$)$ & $0.84(0.24$ to 2.98$)$ \\
\hline Smoking status unknown & 16 & $3.40^{\star}(1.33$ to 8.70$)$ & $3.32^{\star}(1.28$ to 8.60$)$ \\
\hline \multicolumn{4}{|l|}{ Employmentף: } \\
\hline Employed & 33 & 1.0 & 1.0 \\
\hline Left employment & 83 & $0.99(0.66$ to 1.48$)$ & $0.98(0.65$ to 1.49$)$ \\
\hline \multicolumn{4}{|l|}{ All causes excluding lung cancer: } \\
\hline \multicolumn{4}{|l|}{ Type of worker: } \\
\hline Referents & 354 & 1.0 & 1.0 \\
\hline Chrome platers & 346 & $1.10(0.95$ to 1.28$)$ & $1.10(0.95$ to 1.28$)$ \\
\hline \multicolumn{4}{|c|}{ Cigarette smoking: daily habit $(\mathrm{g} /$ day $) \S$ : } \\
\hline Lifelong non-smoker & 112 & 1.0 & 1.0 \\
\hline $1-4$ & 16 & $1.21(0.72$ to 2.04$)$ & $1.20(0.71$ to 2.04$)$ \\
\hline $5-14$ & 149 & $1.26(0.99$ to 1.62$)$ & $1.26(0.98$ to 1.61$)$ \\
\hline $15-24$ & 181 & $1.31^{\star}(1.03$ to 1.66$)$ & $1.31^{\star}(1.03$ to 1.66$)$ \\
\hline$\geqslant 25$ & 84 & $1.64^{\star \star \star}(1.23$ to 2.18$)$ & $1.64^{\star \star \star}(1.23$ to 2.19$)$ \\
\hline Ex-smoker & 80 & $0.97(0.73$ to 1.30$)$ & $0.98(0.73$ to 1.30$)$ \\
\hline Smoking status unknown & 78 & $0.94(0.71$ to 1.26$)$ & $0.94(0.70$ to 1.27$)$ \\
\hline \multicolumn{4}{|l|}{ Employmentף: } \\
\hline Employed & 197 & 1.0 & 1.0 \\
\hline Left employment & 503 & 0.95 (0.80 to 1.12$)$ & $0.99(0.83$ to 1.17$)$ \\
\hline
\end{tabular}

${ }^{\star} \mathrm{p}<0.05 ;{ }^{\star \star} \mathrm{p}<0.01 ;{ }^{\star \star \star} \mathrm{p}<0.001$.

†Separate analysis of the three variables (type of worker, cigarette smoking, employment), each set of relative risks adjusted for sex and age (15-39, 40-44, 45-49, 50-54, 55-59, 60-64, 65-69, 70-74, 75-79, 80-84).

$\neq$ Simultaneous analysis of the three variables, adjusted for sex and age.

\$g/day. Combined use of hand rolled and manufactured cigarettes, manufactured cigarettes were considered to contain $1 \mathrm{~g}$ of tobacco.

TSee footnote*, table 1 . 
workers (Poisson regression), and significantly so also in the matched analysis. The Poisson regression analysis and the matched analysis use an internal standard and it is reasonable to ask which risk estimate is to be preferred (Poisson regression: RR 1.44, (95\% CI 1.00 to 2.08; McNemar's method: RR 1.92 , (95\% CI 1.14 to 3.28)). From the outset it was decided that the findings of the Poisson regression would be given greater weight than those from the matched analysis, because the matched cohort design-although efficient for analysis of all cause mortality-is relatively inefficient for analysis of specific causes.

More comparison workers reported having worked with asbestos $(n=93)$ than did the chrome platers $(n=36) .{ }^{4}$ As these workers are not individually identifiable we cannot determine whether any of the seven deaths from mesothelioma in the comparison workers occurred in the 93 asbestos workers. The seven deaths from mesothelioma would certainly point to much greater exposure to asbestos among the comparison workers than the chrome platers. Asbestos is likely to have caused more deaths from lung cancer than mesothelioma in the comparison workers, ${ }^{14} 1819$ thus underestimating the risk of lung cancer associated with chrome plating (negative confounding). Positive confounding from other previous occupations may have occurred: 231 platers but only 83 comparison workers had worked previously in a foundry, ${ }^{4}$ although again these workers are not individually identifiable. Foundry work is associated with excess risks of lung cancer. ${ }^{20}$ Other concurrent exposures are likely to be less important in the interpretation of the present findings. Recent studies suggest that neither nickel plating nor exposure to cadmium is likely to be an important confounding variable in this study. ${ }^{21-24}$

The study has not shown a positive trend of risks of lung cancer with increasing duration of chrome work, although information on chrome work and work duration after 1972 was unknown for a relatively large group of chrome platers. Also, there was considerable variation in concentrations of chrome in air from factory to factory in this study. Ignoring such variation might lead to some misleading comparisons. Nevertheless, a significant trend has been shown in the prevalence of chrome ulcers with duration of chrome working, ${ }^{4}$ and so the absence of a positive trend with duration of chrome work (particularly in former platers) means that the new findings must be interpreted cautiously.

The greater prevalence of cigarette smoking among the chrome platers than in the general population might contribute to the highly increased SMR for lung cancer but cannot be invoked as the sole explanation. The Poisson regression analyses indicate that chrome plating and cigarette smoking exert independent effects on risks of lung cancer, RRs being similar in separate and simultaneous analyses of these two variables. Confident interpretation is not possible but the size of the SMR for lung cancer and other published studies of chrome platers both weigh in favour of the interpretation that some of the excess SMR for lung cancer in the present study is due to chrome plating.

This paper is dedicated to the memory of the late Dr Harold Royle; some aspects of the approach to occupational health which he followed (description of factory processes, measurewhich he followed (description of factory processes, measurement of factory conditions, analysis of health effects, recommendations for safer working, supervision of remedial measures)
remain a model for current practice. We acknowledge the earlier remain a model for current practice. We acknowledge the earlier
work of the late Dr A M Adelstein in arranging for the tracing of work of the late Dr A M Adelstein in arranging for the tracing of
the cohort and of Dr Sheila Gore in auditing the database; the cohort and of Dr Sheila Gore in auditing the database; responsibility for the study materials as analysed remains with
the current authors. We thank the Office for National Statistics the current authors. We thank the Office for National Statistics
for tracing the cohort and providing death details. We thank for tracing the cohort and providing death details. We thank
Margaret Williams for word processing and Jaswant Bal for computerisation of death details.

1 International Agency for Research on Cancer. IARC Monographs on the evaluation of carcinogenic risks to humans. Vol 49. Chromium, nickel and welding. Lyon: IARC,1990.

2 Waterhouse JAH. Cancer among chromium platers [abstract]. Br f Cancer 1975;32:262.

3 Royle H. Toxicity of chromic acid in the chromium plating industry (1). Environ Res 1975;10:39-53.

4 Royle $\mathrm{H}$. Toxicity of chromic acid in the chromium plating industry (2). Environ Res 1975;10:141-63.

5 Okubo T, Tsuchiya K. An epidemiological study on lung cancer among chromium plating workers. Keio $f$ Med 1977;26:171-7.

6 Okubo T, Tsuchiya K. Epidemiological study of chromium platers in Japan. Biol Trace Elem Res 1979;1:35-44.

7 Silverstein M, Mirer F, Kotelchuck D, et al. Mortality Silverstein M, Mirer F, Kotelchuck D, et al. Mortality
among workers in a die-casting and electroplating plant. Scand f Work Environ Health 1981;7(suppl 4):156-65.

8 Franchini I, Magnani F, Mutti A. Mortality experience Franchini I, Magnani F, Mutti A. Mortality experience
among chromeplating workers. Scand $f$ Work Environ among chromeplating

9 Sorahan T, Burges DCL, Waterhouse JAH. A mortality Sorahan T, Burges DCL, Waterhouse JAH. A mortality
study of nickel/chromium platers. Br f Ind Med 1987;44: $250-8$.

10 Takahashi K, Okubo T. A prospective cohort study of chromium plating workers in Japan. Arch Environ Health 1990; 45:107-11.

11 Sorahan T, Burges DCL, Hamilton L, et al. Lung cancer mortality in nickel/chromium platers, 1946-95. Осcup Environ Med 1998;55:236-42.

12 Horiguchi S, Morinaga K, Endo G. Epidemiological study of mortality from cancer among chromium platers. Asia Pac F Public Health 1990;4:169-74.

13 Royle H. Chromium and its compounds, and the effects of chromic acid exposure on the health of electro-platers in the West Riding of Yorkshire [MD thesis]. London: the West Riding of Yorkshire

14 Peto J, Doll R, Hermon C, et al. Relationship of mortality to measures of environmental asbestos pollution in an asbesmeasures of environmental asbestos pollution in an

tos textile factory. Ann Occup Hyg 1985;29:305-55.
15 EPICURE. Seattle: Hirosoft International Corporation, 1988.

16 Breslow NE, Day NE. Statistical methods in cancer research. Vol II. The design and analysis of cohort studies. Lyon: International Agency for Research on Cancer, 1987. (IARC Scientific Publication no.82.)

17 Office of Population Censuses and Surveys. General household survey 1988. London: The Stationery Office, 1989. (Series GHS no 19.)

18 Newhouse ML, Berry G, Wagner JC. Mortality of factory workers in east London 1933-80. Br F Ind Med 1985;42:411.

19 Newhouse ML, Oakes D, Wooley AJ. Mortality of welders and other craftsmen at a shipyard in NE England. $\mathrm{Br} \mathcal{F}$ Ind Med 1985;42:406-10.

20 Sorahan T, Faux AM, Cooke MA. Mortality among a cohort of United Kingdom steel foundry workers with specohort of United Kingdom steel foundry workers with spe-
cial reference to cancers of the stomach and lung, 1946-90. cial reference to cancers of the stomach
Occup Environ Med 1994;51:316-22.

21 Pang D, Burges DCL, Sorahan T. Mortality study of nickel platers with special reference to cancers of the stomach and lung, 1945-93. Occup Environ Med 1996;53:714-17.

22 Sorahan T, Lister A, Gilthorpe MS, et al. Mortality of copper cadmium alloy workers with special reference to lung cancer and non-malignant diseases of the respiratory system, 1946-92. Occup Environ Med 1995;52:804-12.

23 Sorahan T, Lancashire RJ. Lung cancer mortality in a cohort of workers employed at a cadmium recovery plant in the United States: an analysis with detailed job histories. Occup Environ Med 1997;54:194-201.

24 Jarup L, Bellander T,Hogstedt C, et al. Mortality and cancer incidence in Swedish battery workers exposed to cadmium and nickel. Occup Environ Med 1998;55:755-9. 